\title{
PERBANDINGAN SUPPORT VECTOR MACHINE DAN K-NEAREST NEIGHBOR UNTUK KLASIFIKASI TELUR FERTIL DAN INFERTIL BERDASARKAN ANALISIS TEXTURE GLCM \\ (Comparasion Support Vector Machine And K-Nearest Neighbor for Classification fertile And Infertile Eggs Based on GLCM Texture Analysis )
}

\author{
Dewi Nurdiyah ${ }^{1}$, \\ Fakultas Teknologi Informasi Dan Komunikasi \\ Universitas Semarang \\ e-mail: ${ }^{1}$ nurdiyah@usm.ac.id
}

\author{
Indra Abdam Muwakhid ${ }^{2}$ \\ Sekolah Tinggi Ilmu Ekonomi Selamat Sri Kendal \\ e-mail: ${ }^{2}$ abdam.iam@gmail.com
}

\begin{abstract}
Fertility eggs test are steps that must be performed in an attempt to hatch eggs. Fertility test usually use egg candling. The purpose of observation is to choose eggs fertile (eggs contained embryos) and infertile eggs (eggs that are no embryos). And then fertilized egg will be entered into the incubator for hatching eggs and infertile can be egg consumption. However, there are obstacles in the process of sorting the eggs are less time efficient and inaccuracies of human vision to distinguish between fertile and infertile eggs. To overcome this problem, it can be used Computer Vision technology is having such a principle of human vision. It used to identify an object based on certain characteristics, so that the object can be classified. The aim of this study to comparasion classify image fertile and infertile eggs with SVM (Support Vector Machine) algorithm and K-Nearest Neighbor Algorithm based on input from bloodspot texture analysis and blood vessels with GLCM (Gray Level Co-ocurance Matrix). Eggs image studied are 6 day old eggs. It is expected that the proposed method is an appropriate method for classification image fertile and infertile eggs.
\end{abstract}

Keywords: Classification of fertile and infertile eggs, fertility detection, GLCM texture analysis, Support Vector Machine, K-Nearest Neighbor

\section{PENDAHULUAN}

Usaha penetasan telur, bertujuan untuk menetaskan telur yang memiliki perkembangan embrio yang berupa bloodspot (noktah darah) dan blood vessel (pembuluh darah) yang disebut dengan telur fertil. Sedangkan telur yang tidak memiliki embrio didalamnya disebut telur infertil.

Pengujian fertilitas telur perlu dilakukan untuk menyortir telur untuk dimasukkan ke inkubator. Telur yang dimasukkan ke inkubator adalah telur fertil. Sedangkan telur yang tidak masuk ke inkubator adalah telur infertil yang dapat dimanfaatkan sebagi telur konsumi[5]. Penyortiran telur saat ini masih menggunakan alat teropong telur atau candler, yaitu dengan memberikan cahaya pada telur di ruangan gelap sehingga dapat dilihat telur fertil atau infertil. Namun, penglihatan manusia kurang akurat untuk mengenali telur fertil atau infertil. Masalah ini dapat diatasi dengan computer vision, yakni pengenalan objek suatu citra oleh komputer.

Sebelumnya, telah dilakukan penelitian mengenai klasifikasi telur fertil dan inferrtil oleh Mei Hu Ma (2011) berdasarkan bentuk kuning telur. Jika lonjong maka kemungkinan fertil, dan jika bulat kemungkinan infertil. Metode klasifikasi yang diusulkan adalah LS-SVM (Least Squares Support Vector Machine). Akurasi yg dihasilkan adalah 92,5\%. Kelemahan dari penelitian ini, bentuk telur dipengaruhi oleh ras telur[16]. Jadi, klasifikasi berdasarkan fitur ekstraksi bentuk, masih kurang presisi.

Honjun Zhang, et al (2012) meneliti tentang pengenalan telur infertil sejak dini dalam tahap awal inkubasi. Fitur ekstraksi yang digunakan adalah bentuk kuning telur dan putih telur. Jika area kuning telur lebih kecil dibandingkan putih telur maka telur infertil. Dan jika area kuning telur lebih besar dari pada putih telur maka dikenali sebagai telur fertil. kemudian setelah didapakan fitur ekstraksi tersebut, diklasifikasikan dengan menggunakan algoritma $B P$ (Backpropagation). untuk pengambilan gambar secara horisontal akurasi klasifikasi yang dihasilkan adalah $83,57 \%$. Sedangkan untuk pengambilan gambar secara vertikal akurasi klasifikasi yang dihasilkan adalah $97.86 \%$. Kelemahan dari penelitian ini, bentuk telur dipengaruhi oleh ras telur[12]. Jadi, klasifikasi berdasarkan fitur ekstraksi bentuk, masih kurang presisi dan citra yang didapatkan saat proses pengambilan citra berbeda sehingga mempengaruhi hasil akurasi klasifikasi

Dewi Nurdiyah (2015) telah meneliti klasifikasi telur fertil dan infertil dengan analisis teksur GLCM dan SVM. Hasil akurasi yang dihasilkan 93,2\% [17].

\section{RUMUSAN MASALAH}

Ketidakakuratan atau ketidak telitian penglihatan manusia untuk mengenali telur fertil dan telur infertil dalam proses penyortiran. Sehingga, membutuhkan parameter berupa bloodspot dan blood vessel untuk klasifikasi citra telur fertil dan infertile kemudian membandingkan tingkat akurasi ketepatan klasifikasi dengan metode SVM dan KNN

\section{TUJUAN}


Tujuan penelitian ini adalah

1. Memudahkan masyarakat khusunya dibidang peternakan, untuk menyortir telur fertil dan infertil.

2. Analisis tekstur telur berdasarkan hasil segmentasi area bloodspot dan pembuluh darah dengan GLCM, kemudian mengklasifikasikan telur fertil dan infertil dan membadingkan tingkat akurasi dengan SVM dan KNN.

\section{MANFAAT}

Manfaat dari penelitian ini adalah

1. Memudahkan masyarakat khusunya dibidang peternakan, untuk menyortir telur (membedakan telur fertil dan infertil) sehingga menghemat waktu dan ketelitian lebih terjamin.

2. Meningkatkan keakuratan uji fertilitas telur berdasarkan bloodspot dan pembuluh darah. Karena pada penelitian sebelumnya uji fertilitas hanya berdasarkan bloodspot atau pembuluh darah dan bentuk kuning telur [1][2][9][10].

\section{TINJAUN PUSTAKA}

\subsection{Peneropongan Telur}

Peneropongan telur atau disebut juga dengan istilah candling adalah kegiatan penyortiran telur dengan cara memberikan cahaya pada telur dalam ruangan gelap untuk melihat embrio guna membedakan telur fertil dan infertil. Jika telur tersebut fertil maka terdapat embrio, jika telur infertil maka tidak terdapat embrio.

\subsection{Ruang Warna RGB}

Ruang warna RGB biasa diterapkan pada monitor CRT dan kebanyakan sistem grafika komputer. Komponen dasar ruang warna ini adalah $\mathrm{R}$ (red atau merah), G (green atau hijau) dan B (blue atau biru). Setiap piksel pada citra tersusun oleh ketiga warna ini. Ruang warna RGB dapat memiliki resolusi 24bit. Jumlah warna mencapai 16.777.216.

\subsection{Ruang Warna YIQ}

Ruang warna YIQ juga dikenal dengan nama ruang warna NTSC, dirumuskan oleh NTSC ketika mengembangkan sistem televisi berwarna di amerika serikat. Pada model ini Y disebut luma (yang menyatakan luminans) dan I serta Q disebut chroma. Konversi RGB ke YIQ sebagai berikut [8]

$$
Y=0.299 * R+0.587 * G+0.114 * B
$$

$\mathbf{I}=0.596 * \mathbf{R}-0.274 * \mathbf{G}-\mathbf{0 . 3 2 2} * \mathbf{B}$

$\mathbf{Q}=0.211 * \mathbf{R}-0.523 * \mathbf{G}+0.312 * \mathbf{B}$

5.4 Analisis Tekstur dengan GLCIV
GLCM (Gray Level Coocurance Matrix) adalah analisis tekstur dengan metode statistik, GLCM menghasilkan atribut berikut:

1. Kontras

Kontras adalah banyaknya keberagaman intesitas dalam citra

$$
\text { contrast }=\sum^{N-1} P_{i, j}(i-j)
$$

2. Homogenitas

Homogenitas adalah ketidakseragaman intensitas dalam suatu citra. Homogenitas merupakan invers dari kontras

$$
\text { hom ogeneity }=\sum_{i, j=0}^{N-1} \frac{P_{i, j}}{1+(i-j)^{2}}
$$

3. Energi

Energi adalah ukuran konsentrasi pasangan dengan intensitas keabuan tertentu pada matriks.

$$
A S M=\sum^{N-1} P_{i, j}{ }^{2}
$$

4. Entropi

Entropi adalah pengukuran keteracakan dari distribusi intensitas

$$
\text { entropy }=\sum_{i, j=0}^{N-1} P_{i, j}\left(-\ln P_{i, j}\right)
$$

5. Mean (Rata-rata)

Rata-rata adalah suatu sebaran nilai intensitas citra keabuan

$\mu_{i}=\sum_{i, i=0}^{N-1} i\left(P_{i, j}\right) ; \mu_{j}=\sum_{i, j=0}^{N-1} j\left(P_{i, j}\right)$

6. Korelasi

Korelasi adalah ukuran dependen piksel terhadap piksel tetangga dalam citra

$$
\text { correlation }=\sum_{i, j=0}^{N-1} P_{i, j}\left[\frac{\left(i-\mu_{i}\right)\left(j-\mu_{j}\right)}{\sqrt{\left(\sigma_{i}^{2}\right)\left(\sigma_{j}^{2}\right)}}\right]
$$

\section{Varian}


varians adalah sebaran nilai piksel pada bidang citra

$$
\operatorname{var}=\sigma_{i}^{2}=\sum_{i, j=0}^{N-1} P_{i, j}\left(i-\mu_{i}\right)^{2}
$$

8. Cluster Shade

Dalam cluster shade memungkinkan untuk mengurangi jumlah operasi pada matriks mxn yang terdapat $G$ derajat keabuan dari 0 sampai G-1.

$$
S H A D E=\sum_{i=0}^{G-1} \sum_{j=0}^{G-1}\left\{i+j-\mu_{i}-\mu_{j}\right\}^{3} \times P(i, j \mid \Delta x, \Delta y)
$$

9. Cluster Prominance

$$
P R O M=\sum_{i=0}^{G-1} \sum_{j=0}^{G-1}\left\{i+j-\mu_{i}-\mu_{j}\right\}^{4} \times P(i, j \mid d
$$

Keterangan :

$\mathrm{P}(\mathrm{i}, \mathrm{j})$ menyatakan probabilitas nilai pada baris $\mathrm{i}$ dan kolom j

$\mathrm{N}$ menyatakan banyaknya data

$\mathrm{G}$ menyatakan banyaknya derajat keabuan

$\mu$ menyatakan rata-rata dari nilai $\mathrm{P}$

\subsection{Klasifikasi SVM}

SVM sebenarnya adalah hyperplane linier yang hanya bekerja pada data yang dipisahkan secara linier. Untuk data yang distribusi kelasnya tidak linier, bisanya menggunakan pendekatan pada fitur data awal set data. Kernel dapat didefinisikan suatu fungsi yang memetakan fitur data dari dimensi awal (rendah) ke fitur baru degan dimensi yang relatif lebih tinggi. untuk prediksi set data dengan dimensi fitur baru sebagai berikut

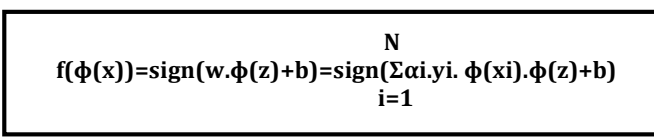

$\mathrm{N}$ adalah jumlah data yang menjadi support vektor, xi adalah support vektor, $\mathrm{z}$ adalah data uji yang akan dilakukan prediksi, b adalah bias, $\alpha$ i adalah data latih pada indeks ke-i dan yi adalah label pada indeks ke-i.

\subsection{Klasifikasi K-Nearest Neighbor}

Metode KNN menjadi metode tertua berbasis NN. Nilai K menyatakan jumlah tetangga terdekat yang dillibatkan dalam penentuan prediksi label kelas data uji. Dari $\mathrm{K}$ tetangga terdekat yang terpilih kemudian dilakukan voting kelas dari $\mathrm{K}$ tetangga terdekat tersebut. Kelas dengan jumlah suara tetangga terbanyaklah yang diberikan sebagai label kelas hasil prediksi pada data uji tersebut.

Algoritma KNN :

$\mathrm{z}=\left(\mathrm{x}^{\prime}, \mathrm{y}^{\prime}\right)$ adalah data uji dengan data $\mathrm{x}^{\prime}$ dan label kelas y' yang belum diketahui.

$\mathrm{C}$ adalah himpunan label kelas data.

Hitung jarak $\mathrm{d}\left(\mathrm{x}^{\prime}, \mathrm{x}\right)$, jarak diantara data uji z ke setip vektor data latih, simpan $D$.

Pilih Dz irisan himpunan D, yaitu K tetangga terdekat dari $\mathrm{z}$.

$\mathrm{Y}^{\prime}=\arg \max \sum$ yi $€ \mathrm{Dz} I(\mathrm{v}=\mathrm{yi})$

$$
\mathrm{V} € \mathrm{C}
$$

\section{VI.HASIL DAN PEMBAHASAN}

Berikut adalah diagram alir penelitian klasifikasi citra telur fertil dan infertil yang meliputi membaca citra RGB, segmentasi citra dengan mengkonversikannya menjadi ruang warna YIQ, proses segmentasi blood spot dan pembuluh darah. Setelah citra segmentasi didapatkan, langkah selanjutnya adalah analisis tekstur dengan menggunakan GLCM, sehingga didapatkan nilainilai statistik dari masing-masing citra. Langkah terakhir adalah klasifikasi citra dengan SVM Linier dan polinomial.

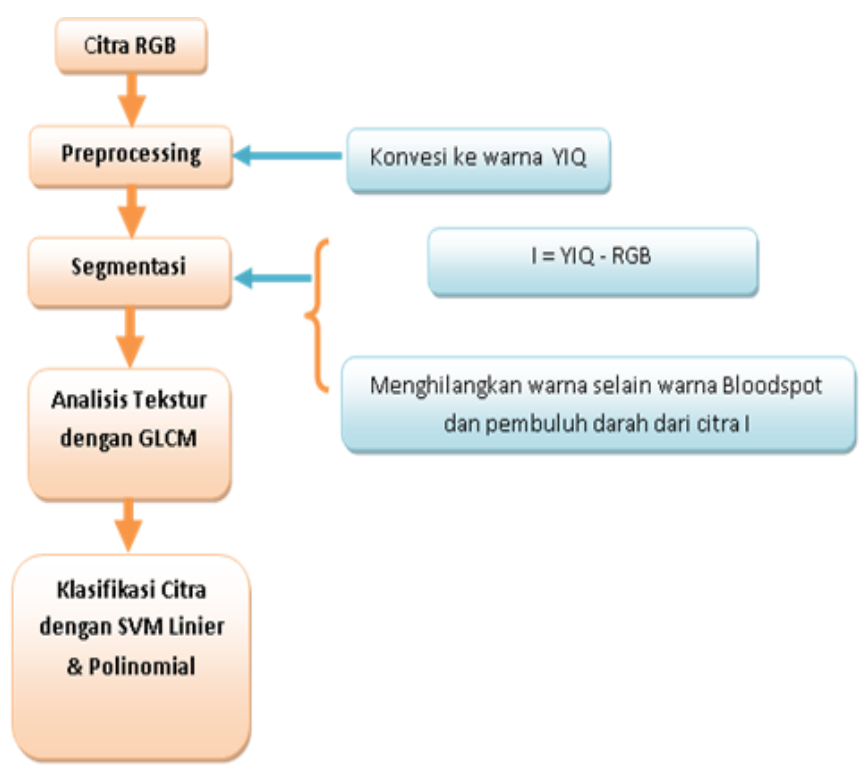

Gambar 1. Diagram alir penelitian

\subsection{Pengambilan Citra}

Sample citra yang diambil adalah telur bebek berumur 6 hari berjumlah 210 data. 112 citra fertil, 98 citra infertil. Untuk memotret telur membutuhkan alat teropong atau candler. Alat teropong dibuat menggunakan kardus yang tertutup rapat. Panjang alat teropong $21 \mathrm{~cm}$, tinggi $40 \mathrm{~cm}$, lebar $21 \mathrm{~cm}$. didalam alat teropong tersebut diberikan lampu untuk menyinari telur, dan dibagian atas alat teropong diberikan lubang dengan diameter $2 \mathrm{~cm}$ untuk tempat 
memotret telur yang telah disinari. ilustrasi alat teropong yang dibuat sebagai berikut

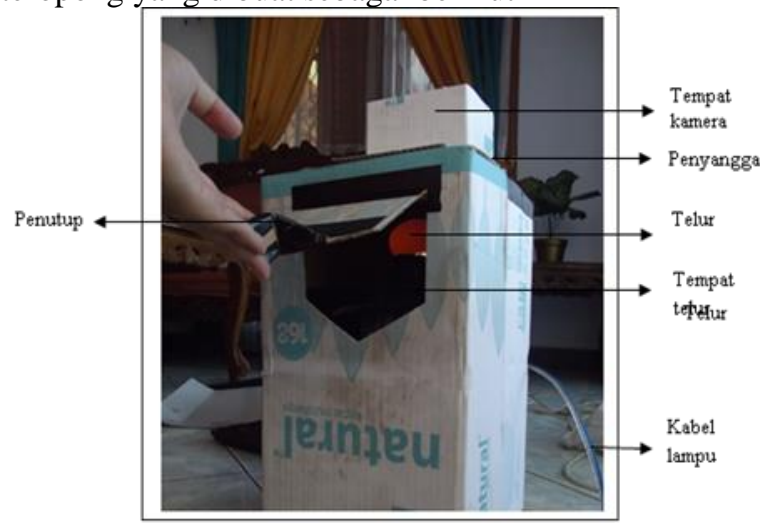

Gambar 2. Alat teropong atau candler

Berikut spesifikasi alat untuk mengambil citra telur:

a. Kamera : FUJIFILM Finepix S2950 14 mega piksel

b. Lampu : Sinar putih 5 watt

c. Kabel : 1 meter

d. Candler

Berikut langkah-langkah pengambilan citra telur :

a. Pemasangan kamera di tempat kamera, setting kamera menjadi potrait

b. lampu candler dalam kondisi menyala

c. telur ditempat telur

d. candler dalam kondisi tertutup

e. Potret telur

Hasil pengambilan citra

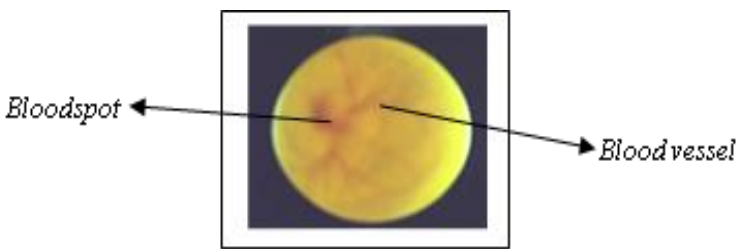

Gambar 3. Citra telur

\subsection{Segmentasi Citra}

Dalam beberapa kali uji coba yang penulis lakukan, segmentasi dengan pengurangan nilai YIQ dengan RGB memberikan hasil terbaik dibanding dengan menggunakan beberapa algoritma thresholding. Namun masih terdapat noise warna. Hal ini dapat dengan mudah dihilangkan dengan cara memberikan kondisi berdasarkan maksimal nilai warna blood spot dan pembuluh darah. Jika warna $\mathrm{r}>$ 0 dan warna $b>0$, maka digantikan oleh warna hitam, sehingga menjadi background. Langkah-langkah segmentasi sebagai berikut :

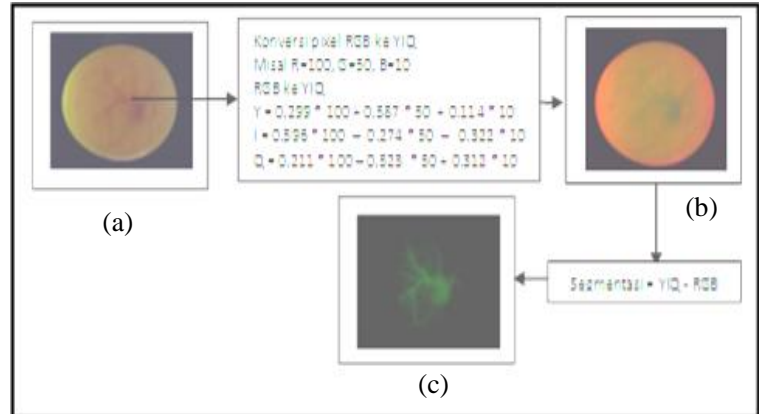

Gambar 4 Proses segmentasi citra. a) citra asli. b) citra YIQ. c) hasil segmentasi

\subsection{Analisis Tekstur GLCM}

Citra yang telah disegmentasi seperti pada gambar 4(c) kemudian dihitung nilai atribut GLCM yang berupa kontras, homogenitas, energi, entropi, mean, autokeralasi, varian, clustershade dan clusterprominance, seperti tabel berikut.

Tabel 1. Nilai atribut GLCM

\begin{tabular}{|l|l|l|}
\hline $\begin{array}{l}\text { Kontrasmax }= \\
0,0042\end{array}$ & $\begin{array}{l}\text { Entropimax }= \\
0,1344\end{array}$ & $\begin{array}{l}\text { Varianmax }= \\
3,7595\end{array}$ \\
\hline $\begin{array}{l}\text { Kontrasmin }= \\
0,0040\end{array}$ & $\begin{array}{l}\text { Entropimin }= \\
0,1339\end{array}$ & $\begin{array}{l}\text { Varianmin }= \\
3,7613\end{array}$ \\
\hline $\begin{array}{l}\text { Homogenitasmax } \\
\text { 0,9978 }\end{array}$ & $\begin{array}{l}\text { Rata-ratamax }= \\
2,0475\end{array}$ & $\begin{array}{l}\text { Clustershadem } \\
\text { ax }=0,1648\end{array}$ \\
\hline $\begin{array}{l}\text { Homogenitasmin } \\
=\end{array}$ & $\begin{array}{l}\text { Rata-ratamin }= \\
0,9979\end{array}$ & $\begin{array}{l}\text { Clustershadem } \\
\text { in=0,165 }\end{array}$ \\
\hline $\begin{array}{l}\text { Energimax }= \\
0,9493\end{array}$ & $\begin{array}{l}\text { Autokorelasimax } \\
=\end{array}$ & $\begin{array}{l}\text { Clusterpromin } \\
\text { ancemax }=0,31 \\
84\end{array}$ \\
\hline $\begin{array}{l}\text { Energimin }= \\
0,9495\end{array}$ & $\begin{array}{l}\text { Autokorelasimin }= \\
1,0692\end{array}$ & $\begin{array}{l}\text { Clusterpromin } \\
\text { ancemin }=0,31 \\
88\end{array}$ \\
\hline
\end{tabular}

\subsection{Pengukuran Kinerja Klasifikasi}

Dari 210 set data fertil dan infertil, peneliti mengambil sample secara acak. data latih $75 \%$, yakni 151 dan data uji 25\%, yakni 59. Pengukuran kinerja klasifikasi dengan menggunakan rumus akurasi dari matriks konfusi, sebagai berikut

Akurasi $=($ Jumlah benar / Jumlah data uji $) \times 100 \%$ (14) 
Tabel 2. Pengukuran Kinerja Klasifikasi SVM

\begin{tabular}{|l|l|l|}
\hline No & SVM Kernel & Akurasi \\
\hline 1 & Polinominal & $93,2 \%$ \\
\hline 2 & MLP & $89,8 \%$ \\
\hline 3 & RBF & $89,8 \%$ \\
\hline 4 & Linier & $88,1 \%$ \\
\hline 5 & LS-SVM & $65 \%$ \\
\hline
\end{tabular}

Tabel 3 Pengukuran Kinerja Klasifikasi KNN, $\mathrm{K}=10$

\begin{tabular}{|l|l|l|}
\hline No & Jarak & Akurasi \\
\hline 1 & Euclidean & $91,5 \%$ \\
\hline 2 & Correlation & $91,5 \%$ \\
\hline
\end{tabular}

\section{PENUTUP}

Pendekatan SVM kernel non linier polinominal lebih bagus dibanding kernel linier dan pendekatan dari paper pembanding [10]. Yakni 93,2\% . hal ini diilustrasikan seperti gambar berikut

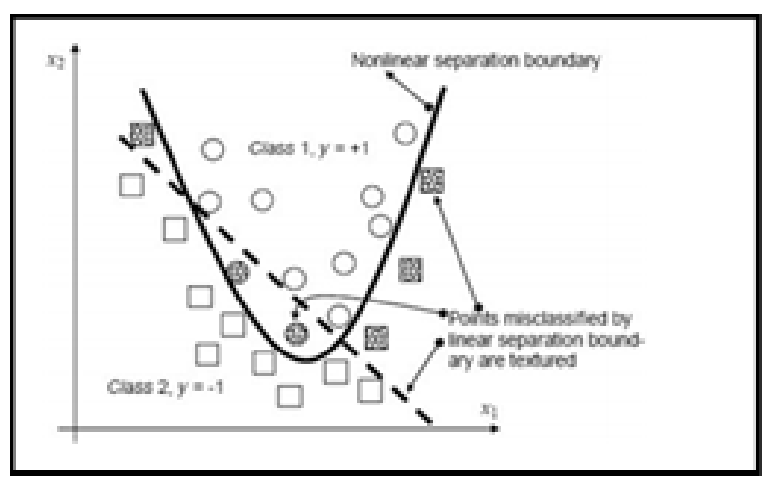

Gambar 2.5 Ilustrasi hyperplane kernel linier dan nonlinier

Garis putus-putus pada Gambar 2.5 menunjukan hyperplane atau pemisah untuk kernel linier, sedangkan kurva pada gambar tersebut menunjukan hyperplane untuk kernel nonlinier. Dari ilustrasi gambar tersebut dapat dilihat bahwa hyperplane yang berbentuk kurva mampu mengklasifikasikan secara benar data yang diklasifikasikan salah oleh kernel linier.

Pendekatan dengan metode KNN dengan jarak euclidean dan correlation menghasilkan akurasi 91,5\%. Hal ini berarti pendekatan dengan metode SVM polinomial lebih unggul dibanding KNN
Jurnal

[1] Arivazhagan, S.et al, "External and Internal Defect Detection ofEgg using Machine Vision", Journal of Emerging Trends in Computing and Information Sciences, Vol. 4, No. 3, 257-262, 2013

[2] Boaming Shan, "Fertility Detection of Middle Stage Hatching Egg in Vaccine Production Using Machine Vision", IEEE Journal. DOI 10.1109/ETCS.2010.540,2010

[3] Chairunnisa Adhisti Prasetiorini.dkk, "Pengenalan Iris Mata Menggunakan Jaringan Saraf Tiruan Metode Perambatan Balik dengan Pencirian Matriks Ko-okurensi Aras Keabuan (Gray Level Co-ocurance Matrix - GLCM), Tugas Akhir Teknik Elektro Universitas Diponegoro, 2013

[4] C.Mythili. et al, "Color Image Segmentation Using ERKFCM",Internation Journal of Computer Application, Vol 41. No 20, March 2012

[5] Ena Winarti, "Peluang Telur Infertil pada Usaha Penetasan Telur Itik Sebagai Telur Konsumsi",Jurnal Seminar Nasional Teknologi Peternakan dan Veteriner, 2005

[6] Fritz Albergsten, "Statistical Texture Measures Computed from Gray Level Coocurrence Matrices", Journal Image Processing Laboratory University of Oslo, 2008

[7] Gleb Beliakov, "Texture Recognation by Using GLCM and Various Agregation Function", IEEE Journal,E-ISBN.978-1-4244-1819-0, 2008

[8] Hongjun Zhang. et al, "A New Method to Recognize Unfertilized Egg in Early Incubation Stage", Trans Tech Publiction Switzerland, CIS Journal, Applied Mechanics and Materials Vols. 121-126, 2012

[9] Ir.Apriani Kusumawardhani,M.cs, "Rancang Bangun Sistem Deteksi Embrio Pada Telur Menggunakan Webcam", JURNAL TEKNIK POMITS Vol .1, No.1, 2012

[10] Mei Hu Ma, "The Identification of White fertile Eggs Prior to Incubation Based on Machine Vision and Least square", African Journal of Agricultural Research, Academic Journal, Vol. 6(12), pp. 2699-2704, 2011

[11] Na Bian, "Evaluation of Texture Futures for Analysis of Ovarian Follicular Development", thresis, University of Saskatchewan Saskatoon, Canada, 2005

[12] Rosena Yusuf, "Karakteristik Morfologi Dan Kualitas Telur Ayam Lokal Khas Dayak Dari Kabupaten Berau Kalimantan Timur”, Jurnal Teknologi Pertanian 7(2):74-80, ISSN 18582419,2012 


\section{Buku}

[13] Kadir,Abdul.Susanto,Adhi.(2013).Teori dan Apilaksi Pengolahan Citra.Yogyakarta. Penerbit ANDI.

[14] Prasetyo,Eko.(2012). Data Minning Konsep dan Aplikasi Menggunakan MATLAB. Yogyakarta. Penerbit ANDI.

[15] Prasetyo,Eko.(2014). Data Minning Mengolah Data Menjadi Informasi Menggunakan MATLAB. Yogyakarta. Penerbit ANDI.

\section{Artikel dari Internet}

[16] Myrka Hall Bayer, "The GLCM Tutorial Home Page", www.fp.ucalgary.ca diakses tanggal 2 November 2014

Tesis

[17] Dewi Nurdiyah, "Klasifikasi Citra Telur fertil dan Infertil Berdasarkan Analisis Tekstur Gray Level Co-occurence Matrix dan Support Vector Machine", tesis, Universitas Dian Nuswantoro Semarang,, 2015 